\title{
Use of Balloon-Tipped Catheters in the Critically III Child
}

\author{
Kenneth M. Weesner, M.D., Albert P. Rocchini, M.D., Amnon Rosenthal, M.D.
}

\begin{abstract}
A retrospective study of our experience in the placement of 19 consecutive balloon-tipped catheters in the pulmonary artery of 18 children disclosed that the procedure can be performed with relative ease in the intensive care unit without the aid of fluoroscopy. Insertion of the catheters was not associated with any serious complications. Catheter malfunction, however, occurred in 9 of 18 patients: balloon rupture in 6 and clot formation in 3. Comparison of pulmonary capillary pressure through a balloon-tipped catheter and venous pressure through a central venous line indicates that, in the absence of significant pulmonary disease requiring high positive end expiratory pressure, or significant left heart dysfunction, a central venous pressure line is frequently adequate for monitoring right heart pressures and as a guidance to fuid therapy.
\end{abstract}

VER THE LAST DECADE, the use of balloon-tipped catheters has become a common aid in assessing fluid status and cardiac function in critically ill adults. ${ }^{1}$ The use of these catheters in critically ill children and neonates has been reported recently. ${ }^{2,3}$ The purpose of this report is to summarize our experience with the use of balloon-tipped catheters in children and to discuss the indications for the use of these catheters.

\section{Methods}

Balloon-tipped catheters were inserted under emergency conditions in 18 children admitted

From the Section of Pediatric Cardiology, C. S. Mott Children's Mospital, University of Michigan Medical Center, Ann Arbor, Michigan.

Correspondence to: Albert P. Rocchini, M.D., Pediatric Cardiology, C. S. Mott Children's Hospital, F1115 Box 66 University of Michigan Medical Genter, Ann Arbor, Michigan 48109.

Received for publication May, 1981; revised August and October, 1981; and accepted October, 1981. to the intensive care unit at the C. S. Mott Children's Hospital between January 1979 and April 1980. Hospital records of each of these children were reviewed for information regarding hospital course and evidence for catheterrelated complications including arrhythmias, infections, and pulmonary infarctions.

All 18 patients had the catheters placed percutaneously without fluoroscopy. In 15 of 18 patients, catheter placement was via the right femoral vein, two via the anticubital vein, and one via an internal jugular vein. Placement in the pumonary artery was confirmed by pressure monitor and portable chest $x$-ray. Catheters used included \#5 French Swan-Ganz catheters in seven, \#6 French Swan-Ganz catheters in two, \#5 Thermodilution catheter in one, and \#7 French Thermodilution catheters in eight patients. After the catheter position was confirmed by $x$-ray, the catheter was secured in the following manner: the introducer sheath was re- 
BALLOON-TIPPED CATHETERS

Table 1. Pertinent Clinical Findings and Pressure Measurements with Ballow-Tipted Catheter in the Pulmonary Artery of 18 Critically lll Children

\begin{tabular}{|c|c|c|c|c|c|c|c|c|}
\hline Patient & Diagnosis & $\begin{array}{l}\text { Age } \\
\text { (yrs) }\end{array}$ & $\begin{array}{l}\text { Time } \\
\text { Catheter in } \\
\text { (days) }\end{array}$ & Complications & Survived & $\begin{array}{c}P \wedge p^{*} \\
(\mathrm{mmHg})\end{array}$ & $\begin{array}{l}\mathrm{PCW} \mathrm{p}^{*} \\
(\mathrm{mmH})\end{array}$ & $\begin{array}{c}\mathrm{CVP} \\
(\mathrm{mmHg})\end{array}$ \\
\hline 1 & Reye's & 1.5 & 1.0 & none & - & $27 / 9$ & 8 & not \\
\hline 2 & Reye's & 12.5 & 5.0 & lumen occluded & - & 25,12 & 4 & $\pi, 0$ \\
\hline 3 & Reye's & 5.9 & 4.0 & balloon rupture & - & $19 / 10$ & 7 & 6 \\
\hline 4 & Reye's & 2.8 & 5.0 & none & - & $25 / 10$ & 10 & 8 \\
\hline 5 & Reye's & 3.5 & .25 & none & - & $18 / 10$ & 5 & 3 \\
\hline 6 & Reye's & 1.5 & 3.0 & balloon rupture & - & $40 / 20$ & 18 & n.o. \\
\hline 7 & Reye's & 10.9 & 1.0 & balloon rupture & - & $24 / 17$ & 12 & n.o. \\
\hline 8 & Reye's & 11.9 & 1.0 & balloon rupture & + & $15 / 5$ & 4 & 6 \\
\hline 9 & Reye's & 9.0 & 2.0 & balloon rupture & - & $18 / 12$ & 7 & 8 \\
\hline 10 & Reye's & 9.0 & $4.0,4.0$ & balloon rupture & - & $12 / 5$ & 5 & 2 \\
\hline 11 & Reye's & 1.0 & 1.0 & none & + & $18 / 0$ & 3 & 2 \\
\hline 12 & Hemolytic anemia & 12.3 & 2.0 & none & - & 18,8 & 4 & n.o. \\
\hline 13 & Near drowning & 12.0 & 3.0 & none & - & $28 / 17$ & 15 & n.o. \\
\hline 14 & SLE + , respiratory failure & 14.8 & 5.0 & lumen occluded & - & $22 / 12$ & 11 & n.o. \\
\hline 15 & Acute renal failure & 5.3 & 1.0 & none & + & $38 / 28$ & 15 & 15 \\
\hline 16 & Acute aortic insufficiency & 16.4 & 3.0 & none & + & $42 / 27$ & 20 & n.o. \\
\hline 17 & ALL $\$$, pneumonia & 10.9 & 2.0 & none & - & $35 / 25$ & $1 !$ & n.o. \\
\hline 18 & Gram negative sepsis & 0.9 & 2.0 & lumen occluded & - & $28 / 20$ & 8 & 6 \\
\hline
\end{tabular}

* PAp $=$ pulmonary artery pressure, $\mathrm{PCW}=$ pulmonary capillary wedge pressure, $\mathrm{CVp}=$ central venous

moved, sterile gauze and Betadine $e^{(i n t m e n t}$ were applied to the skin exit site, and the catheter was secured to the skin by adhesive tape. The dressings at the skin entry site were changed daily using sterile technique. Catheter patency was maintained by a continuous infusion of heparin solution, $(1 \mathrm{ml} / \mathrm{hr}$ of 1 unit of sodium hep$\operatorname{arin} / \mathrm{ml}$ of $5 \%$ dextrose). All catheterizations were performed by Pediatric Cardiology fellows or staff. Patient 10 (Table 1) required insertion of another catheter using the same access point. This was accomplished by cutting off the catheter, pulling it back to a sterile section and reinserting a sterile sheath over the catheter so that a second catheter could be inserted. Central venous pressure was measured in 9 of 18 patients either via the second lumen of a thermodilution catheter or by an additional central venous pressure catheter.

Initial and subseçuent pulmonary artery pressure, pulmonary capillary, and central venous pressure measurements were recorded. The recordings were made with a calibrated Statham transducer positioned at the midatrial level. The transducers were calibrated using a mercury pressure manometer. Thermodilution cardiac outputs were determined in 8 patients using an Instrumentation Laboratories thermodilution pressure + n.o. $=$ not obtained $\$ S L E=$ Systemic Lupus Erythematosus \& ALL = Acute Lymphocytic Leukemia.

cardiac output computer and $3-7 \mathrm{ml}$ of iced saline at 0 degrees Centigrade.

Patient diagnoses included Reye's syndrome in 11 patients and one patient each with hemolytic anemia, hepatic failure, acute renal failure, severe lupus erythematosus, near drowning, pneumonia, sepsis, and acute aortic insufficiency (Table 1). The age of patients was 11 months to 17 years (mean 4 years).

\section{Results}

The balloon-tipped catheters remained in place for 6 hours to 5 days (mean 2.6 days). Catheter malfunction occurred in 9 of $18 \mathrm{pa}$ tients $(50 \%)$, with balloon rupture in 6 and clot formation in the catheter in 3. Balloon rupture occurred after one to four days (mean 2.7 days). There was no evidence of sepsis, as documented by multiple blood cultures drawn while the catheter was in place. Iniection at the site of catheter placement and peripheral thromboses were not observed. Fourteen of 18 patients died. Postmortem examination was performed in nine of these 14 patients. None were found to have pulmonary emboli, pulmonary infarct, or hemorrhage. The pulmonary valve was normal in all cases. 


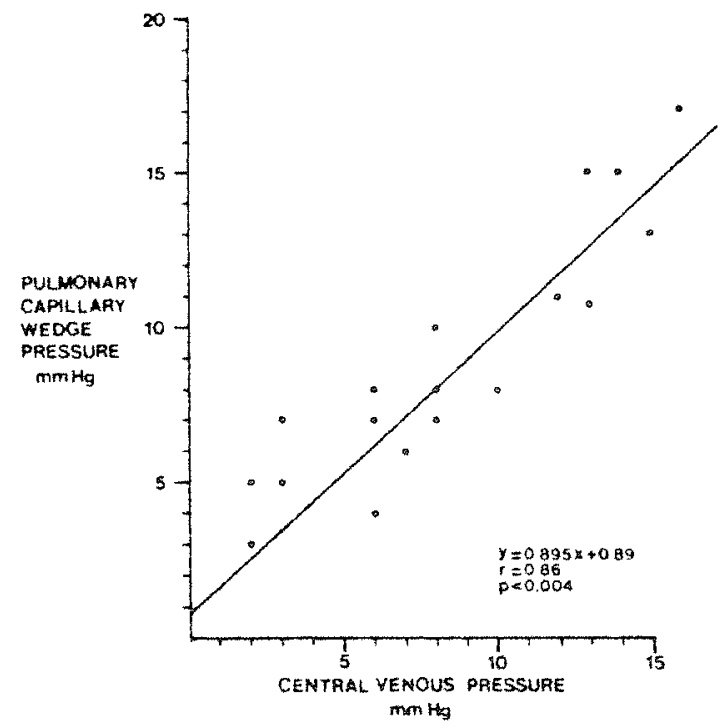

FiG. 1. The relationship between simultaneously measured central venous pressure and pulmonary capillary wedge pressure in nine patients.

Initial peak systolic pulmonary artery pressure was found to be elevated (greater than 30 $\mathrm{mm} H \mathrm{H}$ ) in four of 18 patients and pulmonary capillary pressure elevated (greater than $14 \mathrm{~mm}$ $\mathrm{Hg}$ ) in four of 18 patients. Central venous pressure (greater than $10 \mathrm{~mm} \mathrm{Hg}$ ) was elevated in

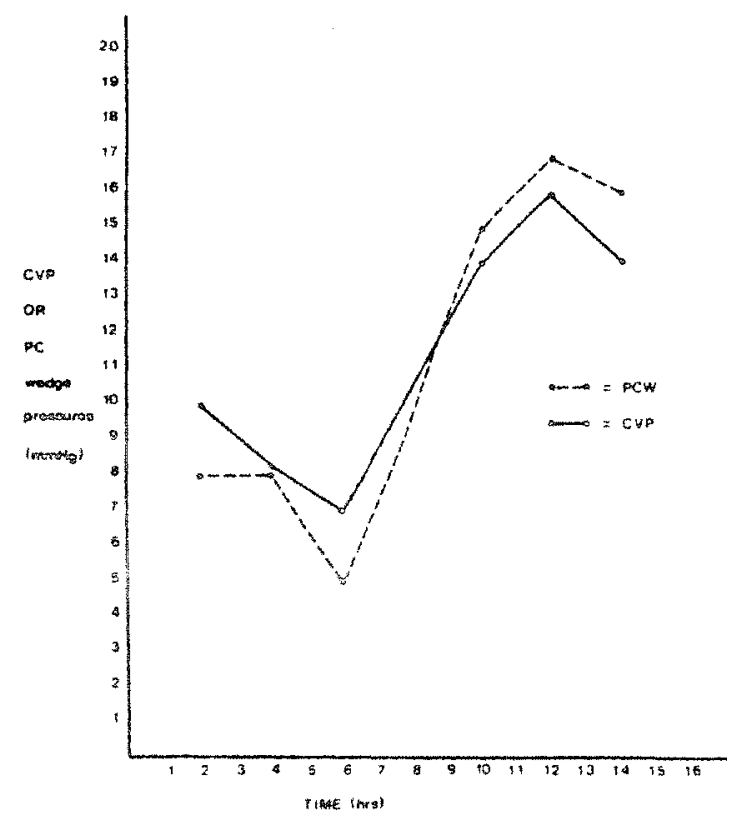

Fic. 2. The relationship between central venous pressure (CVP) and pulmonary capillary wedge pressure (PCW) in patient 4 . only one of the nine patients in whom it was measured. The simultaneous measurements of pulmonary capillary pressure and central venous pressure were made in nine of 18 patients. All nine patients were being ventilated mechanically with a positive end expiratory pressure of less than or equal to $5 \mathrm{~cm}$ of water and had no previous underlying heart disease. A comparison of the 18 simultaneously measured pulmonary capillary and central venous pressures in these nine patients is shown in Figure 1. There was a significant relationship $(r=0.86 ; p<0.004)$ between measured pulmonary capillary pressure and central venous pressure (pulmonary capillary pressure $=0.895 \times$ central venous pressure $+0.89 \mathrm{~mm} \mathrm{Hg}$ ). Figure 2 illustrates the relationship between central venous pressure and pulmonary capillary wedge pressure in one patient, a 2-year-old boy with Reye's syndrome in whom multiple simultaneous values were obtained.

\section{Discussion}

Balloon-tipped catheters were developed over a decade ago to provide hemodynamic information on left ventricular function. ${ }^{4}$ Their use in pediatric cardiac catheterization has become routine and has added to the safety of that procedure in children, ${ }^{5,6}$ Although their use in the critically ill child has only recently been reported, ${ }^{2}$ their popularity has spread to many institutions caring for sick infants and children.

Two of the major drawbacks of using balloontipped catheters in children have been the need for venous cutdown and for fluoroscopy to facilitate passage of the catheter into the pulmonary artery. In addition, thermodilution cardiac catheters are more difficult to manipulate when using the groin approach in infants and children. In all of our 18 patients, including four children under 2 years of age, we were able to place balloon-tipped catheters in the puimonary artery percutaneously and without the aid of fluoroscopy. Recently, it has been reported that twodimensional echocardiography can be useful to localize catheters in cardiac chambers, and to assist in their placement into the pulmonary artery. 'Thus, balloon-tipped catheters can be safely inserted at the bedside, even in sick iniants. 


\section{BALLOON-TIPPED CATHETERS}

While the information on left heart filling pressures, pulmonary artery pressure, and cardiac output obtained through balloon-tipped catheters may be useful in the care of the critically ill child, the procedure may not be totally innocuous. Potential complications of indwelling pulmonary artery catheters are pulmonary parenchymal damage, dysrhythmias, thromboembolic phenomenon, and infection. ${ }^{1}$ The placement of an indwelling catheter in the groin in children also has a potential for severe infection. ${ }^{8}$ With meticulous care of both the entry site and the catheter, we experienced no serious complications in our patients. The complications we did observe were balloon rupture in six, and catheter lumen occlusion in three.

Although we have demonstrated that, in children, a balloon-tipped catheter can be inserted safely and without fluoroscopy, our data also suggest that these catheters may not always be necessary. We observed a linear correlation between central venous pressure and pulmonary capillary wedge pressure (Figs. 1 and 2). Toussaint and co-workers ${ }^{9}$ have also demonstrated a good correlation between central venous pressure and pulmonary capillary pressure in adults without cardiopulmonary disease. In fact, only in the presence of either severe pulmonary disease or severe cardiac disease, do pulmonary capillary wedge pressure and central venous pressure not correlate. ${ }^{10,11}$ Therefore, in the majority of critically ill children, a central venous pressure cannula may be a more reasonable first step.

We conclude that balloon-tipped catheters can be inserted safely without fluoroscopy in chil- dren. However, in the majority of patients without cardiopulmonary involvement, a central venous pressure line may be sufficient to monitor gross cardiac function and fluid therapy. We have particularly found that to be the case in Reye's syndrome, as those patients uniformly had normal simultaneous central venous and pulmonary capillary wedge pressures.

\section{References}

1. Swan HJC, Ganz W: The use of balloon flotation catheters in critically ill patients. Surg Clin North Am 55:501, 1975

2. Pollack MM, Reed TP, Holbrook PR: Bedside pulmonary artery catheterization in pediatrics. I Pediatr $96: 274,1980$

3. Todres ID, Crone RK, Rogers MC, et al: Swan-Ganz catheterization in the critically ill newborn. Crit Care Ned 7:330, 1979

4. Swan HJC, Ganz W, Forrester JS, et al: Catheterization of the heart in man with use of a How-directed balloon tipped catheter. N Engl J Med 283:447, 1970

5. Stranger $P$, Heymann M, Hoffman JIE, et al: Use of Swan-Ganz catheter in cardiac catheterization of infants and children. Am Heart J 83:749, 1972

6. Boutrose AR, Esfandiari $S$, Orlowski JP, et al: Reye's syndrome: A predictably curable disease. Pediatr Clin North Am 27:539, 1980

7. Perry LW, Galioto FM, Blair $T$, et al: 'Two-dimensional echocardiography for catheter location and placement. Circulation 62:74, 1980

8. Asnes RS, Arendar GM: Septic arthritis of the hip: A complication of femoral venipuncture. Pediatrics $38: 837,1966$

9. Toussaint GPM, Burgess JH, Hampson LG: Central venous pressure and pulmonary wedge pressure in critical surgical illness. Arch Surg 109:265, 1974

10. Logman J, Powers SR, Older T, et al: Correlation of pulmonary wedge and left atrial pressure. Arch Surg 109:271, 1974

11. Buda AJ, Prinsky MR, Tugelo NB, et al: Effect of intrathoracic pressure on left ventricular performance. N Engi J Med 301:453, 1979 